Proceedings of the 2nd international conference Economic and Business Trends Shaping the Future | 2021

\title{
CORRELATION OF TOTAL GDP AND NUMBER OF SMALL AND MEDIUM ENTERPRISES IN THE EU-28
}

\author{
Mirjana Štaka \\ Faculty of Economics Banja Luka \\ mirjana.staka@gmail.com
}

\begin{abstract}
Micro, small and medium enterprises play a major role in the country's economic growth and development. The connection and correlation of GDP and the number of small and medium-sized companies represents a key not only economic but also social role of EU countries. This paper seeks to explore small and medium enterprises as an important role in economic growth and development. Micro, small and medium enterprises play a very important role in the economic development of the country, which is the reason for many studies and analyzes. In addition to contributing to gross domestic product creation, they also play a key social role as they reduce unemployment.

The aim of this paper is to assess the relationship between the components of gross domestic product $(G D P)$ and the development of small and medium enterprises (SMEs) in the EU-28 in the years 2009-2019. To achieve this goal, we reviewed the literature, presented statistical data that confirm the importance of these companies in economic development, such as: indicator of entrepreneurship (calculated as the number of SME companies per 1000 inhabitants), participation of SMEs in creating added value. We have presented this data for selected EU countries.

Material and methods of work will be performed statistical analysis of data collected for SMEs in the EU and thus enable verification of the hypothesis set in the paper. Secondary data downloaded from the Eurostat site will be used. Based on the downloaded data and the application of a simple regression model, a universal and original model will be presented. Before presenting the model, a correlation will be made in order to present the comprehensiveness of the model. The model will be presented in the form of a function, which will have the value of parameters on the basis of which the influence of independent variables on dependent ones will be determined.

The results and conclusions are presented at the end of the paper. The results of the research confirm the theoretical significance and role of small and medium enterprises, as well as the need for their internalization and growth into global market leaders. If the unemployment rate increases by 1 unit (if one person loses his job) in the EU, it will cause a decrease in total domestic value (GDP) by 0.509 units. Every new unemployed worker will cost the EU so much unproduced output and new added value. Assuming that there is no unemployment in the EU, ie that the rate is equal to 0, the EU would produce a gross domestic value of 16,135 euros (note: only the impact and the relationship between the unemployment rate and GDP is taken into account here). Thus, it is clear how much costs and effects unemployment has on the gross domestic product and economic policy of EU countries.
\end{abstract}

Keywords: GDP, development, small companies, growth, EU

JEL classification: E01, M13

http://hdl.handle.net/20.500.12188/15924

http://doi.org/10.47063/EBTSF.2021.0012 


\section{INTRODUCTION}

The role of small and medium enterprises (SMEs) in the national economy cannot be underestimated. These companies have received increasing attention in recent years, in part due to growing frustration with the results of development strategies focused on capital-intensive large-scale industrial plants. The impact of SMEs is felt in the following ways: greater use of domestic raw materials, new jobs, encouraging rural development, entrepreneurship development, mobilization of local savings, ensuring regional balance by more even expansion of investments, providing ways for self-employment and training opportunities for managers and semi-skilled workers. The vast majority of developed and developing countries rely on the dynamism, resourcefulness and task of small and medium-sized enterprises to start and maintain the process of economic growth. In the overall economic development, small and medium enterprises play a crucial role (Osborne, 2010). Small and medium-sized enterprises are committed, above all, to withstanding competition and entrepreneurship and therefore to have external benefits for the economy through broader productivity growth. At this level, the perspectives are focused on government support and involvement in reaping the social benefits of countries with greater completion and entrepreneurship. Second, SME advocates support the frequent claims that SMEs are generally more productive than large firms, but the financial market and other institutional improvements, direct government financial support to SMEs can stimulate economic growth and development. Some have argued that the expansion of small and medium-sized enterprises encourages employment more than the large growth of firms. Small and medium enterprises play a crucial role in the economic development of many countries. Business globalization is not a "short-term event" but a "continuous process" with the help of which companies gain experience, get to know the local market, and adjust the intensity of internationalization of their business (Đorđević, 2016). The research problem addresses a key question: Does the number of SMEs have an impact on the GDP of the EU-28? In order to successfully monitor the development path of small and medium enterprises, it is necessary to monitor their performance as factors that determine whether small enterprises will grow into global ones. Labor hypothesis reads H0: There is a significant correlation between the number of small enterprises and the total GDP of the EU-28. Alternative Hypothesis H1: There is a significant correlation between the number of medium-sized enterprises and GDP in EU countries. The time period of the analysis is from 2009 - 2019. adjust and adjust the intensity of internationalization of their business (Đorđević, D. 2016). The research problem addresses a key question: Does the number of SMEs have an impact on the GDP of the EU-28? In order to successfully monitor the development path of small and medium enterprises, it is necessary to monitor their performance as factors that determine whether small enterprises will grow into global ones.

Hypothesis of the work is $\mathrm{H} 0$ : There is a significant correlation between the number of small enterprises and the total GDP of the EU-28.

Alternative Hypothesis H1: There is a significant correlation between the number of mediumsized enterprises and GDP in EU countries.

The time period of the analysis is from 2009 - 2019. adjust and adjust the intensity of internationalization of their business (Đorđević, D. 2016). The research problem addresses a key question: Does the number of SMEs have an impact on the GDP of the EU-28? In order to successfully monitor the development path of small and medium enterprises, it is necessary to monitor their performance as factors that determine whether small enterprises will grow into global ones. Hypothesis of the work is H0: There is a significant correlation between the number 
of small enterprises and the total GDP of the EU-28. Alternative Hypothesis H1: There is a significant correlation between the number of medium-sized enterprises and GDP in EU countries. The time period of the analysis is from 2009 - 2019. Does the number of SMEs have an impact on the GDP of the EU-28? In order to successfully monitor the development path of small and medium enterprises, it is necessary to monitor their performance as factors that determine whether small enterprises will grow into global ones. Labor hypothesis reads H0: There is a significant correlation between the number of small enterprises and the total GDP of the EU-28. Alternative Hypothesis H1: There is a significant correlation between the number of medium-sized enterprises and GDP in EU countries. The time period of the analysis is from 2009 - 2019. Does the number of SMEs have an impact on the GDP of the EU-28? In order to successfully monitor the development path of small and medium enterprises, it is necessary to monitor their performance as factors that determine whether small enterprises will grow into global ones. Labor hypothesis reads H0: There is a significant correlation between the number of small enterprises and the total GDP of the EU-28. Alternative Hypothesis H1: There is a significant correlation between the number of medium-sized enterprises and GDP in EU countries. The time period of the analysis is from $2009-2019$.

\section{PREVIOUS RESEARCH}

The concept and definition of small and medium-sized companies differs from one country to another due to the culture of that country, economic opportunities, the availability of labor in the market and other factors. There are many scientific publications concerning SMEs. Most SMEs are defined or categorized based on the number of employees, the total annual income of the company or the capital invested in the manufacturing sector (Singh, 2010). When it comes to the global framework, it is a widely used term that includes exports / imports, branches, joint ventures, cooperation, subsidiaries (Anderson, 2007). Micro, small and medium-sized companies that exist in the EU-28 countries have a positive impact on overall GDP. EU programs support the development of small and medium-sized enterprises in Europe, which is proof of the importance of SMEs for many economies. there is a growing awareness of their role in the development of a global, regional economy. Numerous authors have published their research on this issue, for example empirical research has confirmed that SMEs, especially those that invest in research and development, tend to have higher productivity and growth intensities than large companies. Several mechanisms explain the impact and importance of why micro, small and medium-sized enterprises play a key role in economic development in EU countries. Especially because these companies in cooperation with large companies can be carriers of innovation and ultimate economic growth. These mechanisms are: knowledge transfer, decentralization, experimentation, competition (Petković, 2013). In developed countries, small businesses have good potential, they often cooperate with larger corporations and industries and strive for greater endeavors, where SMEs are identified as companies characterized by their willingness to boldly innovate, and to take significant risks in their production and marketing strategies. Innovations in this sense reflect the essential readiness of SMEs to move away from existing technologies or practices and to approach new ventures that go beyond the current state of development in certain areas (Sorak, 2017). This implies the willingness of SMEs to creatively initiate and support new ideas and experiments by creating new processes that can result in new quality services and products, these markets. EU countries represent small and medium-sized companies as a driver of economic and social development thanks to the results of significant and exceptional contribution of these companies in increasing GDP, especially in the field of 
employment and job creation. For this reason, SMEs represent 93\% of all companies in the EU28 , ie 22.3 million jobs and business activities, generating $56.4 \%$ of value added, playing a significant role in employment, attracting $2 / 3$ of employees in the business sector. During 2019, SME value added grew to a percentage of $4.1 \%$ in 2019 and $4.2 \%$ in 2020 , while employment decreased from 1.6 in 2019 to $1.4 \%$ in 2020. (European Commission, 2019). Unstable business conditions directly or indirectly affect the competitiveness of these companies. These conditions include investment problems, expensive loans, problems in debt collection, outdated technologies, high levels of corruption and bureaucracy and other political and social problems. Performance is an indispensable guide for any company that analyzes its level of success, both in the domestic and global market. Assessing their performance can follow the development path of small businesses on the path to internationalization and globalization. At the beginning of the XXI century, due to the dynamic development of technology and homogenization of consumers, national markets became narrow, so a large number of companies were forced to expand their business beyond them. The task was to find new markets that became a significant factor in their further growth and development. Competition and tighter business conditions should bring small businesses to the global market, as the only valid confirmation of their efficiency. Accelerated globalization processes, economic and political integrations, development of modern technology and new ways of communication have opened the possibility of development of small and medium enterprises (SMEs), which represent an integral sector of all economies as well as the possibility of their internationalization (Škrtić, 2009). Knowledge of how the corporate environment affects the growth and business of a company creates an opportunity for success in the markets. Therefore, the aim of the article is to assess the relationship between the components of gross domestic product (GDP) and the development of small and medium enterprises, hereinafter (SMEs). The conclusion is that the smaller the company, the stronger the connection. The national economy affects the development of SMEs. Its stability, transparency, continuity, provision of basic economic freedoms and rights are the main determinants of SME development. economic and political integrations, the development of modern technology and new ways of communication have opened the possibility of developing small and medium enterprises (SMEs), which represent an integral sector of all economies as well as the possibility of their internationalization (Śkrtić, 2009). Knowledge of how the corporate environment affects the growth and business of a company creates an opportunity for success in the markets. Therefore, the aim of the article is to assess the relationship between the components of gross domestic product (GDP) and the development of small and medium enterprises, hereinafter (SMEs). The conclusion is that the smaller the company, the stronger the connection. The national economy affects the development of SMEs (Kingman, 1978). Its stability, transparency, continuity, provision of basic economic freedoms and rights are the main determinants of SME development. economic and political integrations, the development of modern technology and new ways of communication have opened the possibility of developing small and medium enterprises (SMEs), which represent an integral sector of all economies as well as the possibility of their internationalization (Škrtić, 2009). Therefore, the aim of the article is to assess the relationship between the components of gross domestic product (GDP) and the development of small and medium enterprises, hereinafter (SMEs) (Cherington, 2005). The conclusion is that the smaller the company, the stronger the connection. The national economy affects the development of SMEs. Its stability, transparency, continuity, provision of basic economic freedoms and rights are the main determinants of SME development. 


\section{METHODOLOGY}

The survey will use secondary data downloaded from the Eurostat website. based on the downloaded data and the application of a simple regression model, a universal and original model will be presented. before presenting the model, a correlation will be made in order to present the comprehensiveness of the model. The model will be presented in the form of a function, which will have the value of parameters on the basis of which the influence of independent variables on dependent ones will be determined. The subject of this paper is the analysis of the impact of small and medium companies on GDP growth. Taking these indicators into account, they try to find a connection between small and medium-sized companies and GDP. Examining the impact and relationship between the number of SMEs, on the one hand, and economic strength, on the other, can be demonstrated using a single linear regression model. for this purpose, as a dependent variable (regressive, explained, exogenous) representing GDP, while dependent variables (regressive, explained, explanatory, endogenous) representing the number of small and medium-sized companies in the EU market. The paper will present the correlation, regression, determination, $\mathrm{F}$ test on the significance (significance) of the model.

$$
Y_{i}=\beta_{0}+\beta_{1} * X_{1 i}+\varepsilon_{i}{ }^{1}(i=1, . n)
$$

$\beta \mathrm{o}, \beta 1=$ regression parameters to be evaluated $\varepsilon \mathrm{i}=$ stochastic term (random deviation, error or residual) $\mathrm{n}=$ size, number of base sets to evaluate a single linear regression model means to find the value of the parameters $\beta$ o and $\beta 1$, ie to find the estimated value of the model is:

$$
\widehat{\mathrm{Y}}_{\mathrm{i}}=\widehat{\mathrm{b}}_{0}+\widehat{\mathrm{b}}_{1} \mathrm{X}_{1 \mathrm{i}}
$$

The linear dependence can be estimated on the basis of the model:

$$
\hat{Y}_{\mathrm{i}}=\mathrm{b}_{0}+\mathrm{b}_{1} \mathrm{X}_{1 \mathrm{i}}, \mathrm{i}=1, \ldots, 11
$$

The model takes the numbers of small and medium-sized companies as an independent variable and examines its impact on GDP trends. The result of the regression analysis shows the degree of influence of small and medium-sized enterprises on GDP growth. Regression analysis is a standard statistical procedure. This method is simple and reliable (for example, mutually excludes positive and negative errors). For the purposes and for the purpose of calculation, the average linear correlation is the best direction of presentation of the observed variables. Pearson's correlation coefficient for private consumption according to the degree of strength is 0.942 , which can be characterized as a very strong correlation. It also shows that there is a linear connection and a continuous normal distribution. The result of the regression analysis shows the degree of influence of small and medium-sized enterprises on GDP growth. Regression analysis is a standard statistical procedure. This method is simple and reliable (for example, it mutually excludes positive and negative errors). For the purposes and for the purpose of calculation, the average linear correlation is the best direction of presentation of the observed variables. Pearson's correlation coefficient for private consumption according to the degree of strength is 0.942 , which can be characterized as a very strong correlation. It also shows that there is a linear

\footnotetext{
${ }^{1}$ The single linear regression model has a deterministic and stochastic segment. the deterministic segment refers to the average influence of the independent (x) and dependent (y) variables, the parameter $\beta 0$ is the free term and the $\beta 1$ slope coefficient
} 
connection and a continuous normal distribution. The result of the regression analysis shows the degree of influence of small and medium-sized enterprises on GDP growth. Regression analysis is a standard statistical procedure. This method is simple and reliable (for example, it mutually excludes positive and negative errors). For the purposes and for the purpose of calculation, the average linear correlation is the best direction of presentation of the observed variables. Pearson's correlation coefficient for private consumption according to the degree of strength is 0.942 , which can be characterized as a very strong correlation. It also shows that there is a linear connection and a continuous normal distribution. For the purposes and for the purpose of calculation, the average linear correlation is the best direction of presentation of the observed variables. Pearson's correlation coefficient for private consumption according to the degree of strength is 0.942 , which can be characterized as a very strong correlation. It also shows that there is a linear connection and a continuous normal distribution. For the purposes and for the purpose of calculation, the average linear correlation is the best direction of presentation of the observed variables. Pearson's correlation coefficient for private consumption according to the degree of strength is 0.942 , which can be characterized as a very strong correlation. It also shows that there is a linear connection and a continuous normal distribution.

\section{SMALL AND MEDIUM ENTERPRISES AND TOTAL GDP OF EU-28 COUNTRIES: STATISTICAL ANALYSIS}

\subsection{Trend analysis GDP}

Gross domestic product (GDP) is most often used as a measure of the total size of the economy, while derived indicators, such as GDP per capita (per capita) - for example, in euros. Furthermore, useful information can be obtained from the development of certain components of GDP and related indicators, such as indicators of economic product, imports and exports, domestic (private and public) consumption or investment, as well as data on the distribution of income and savings. on the main drivers of economic activity, which can be used to develop, monitor and evaluate specific EU policies.

Figure 1: Real GDP growth for EU countries 2009-2019.

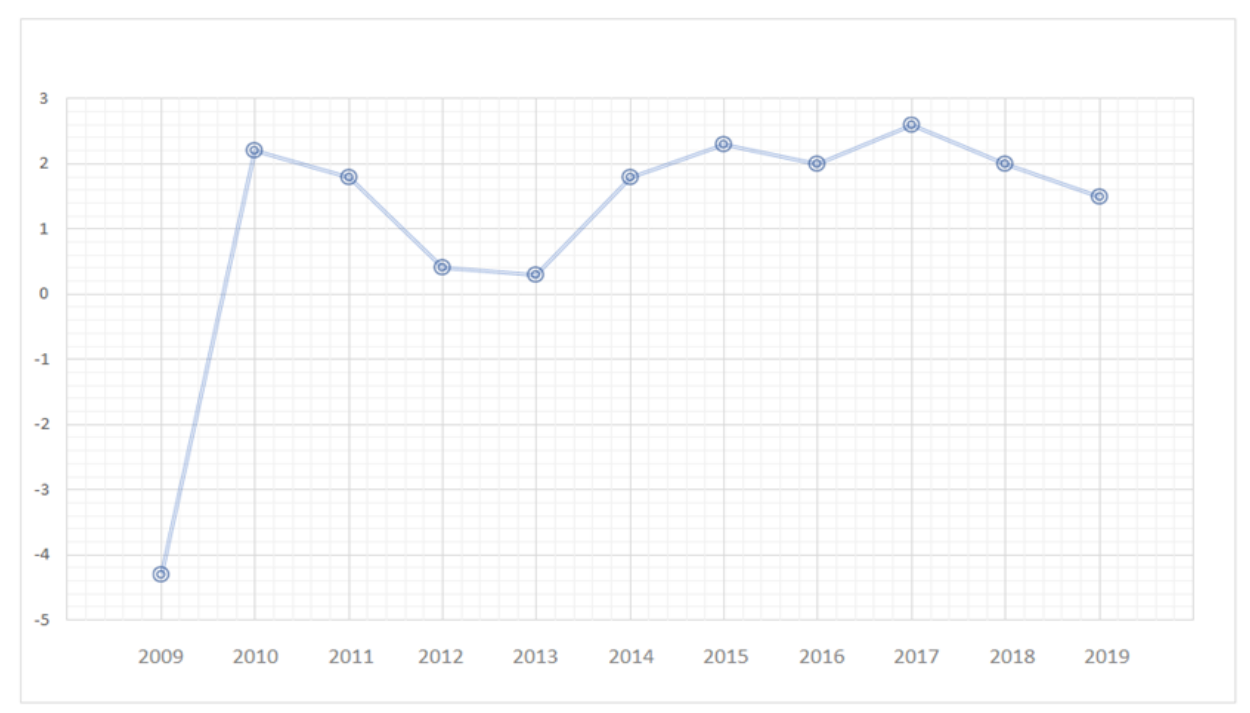

Source: Eurostat 
The aftermath of the global economic crisis in 2009 recorded and left an impact on EU countries and GDP. Apart from the fall in GDP and the low growth rate, the tendency of the GDP structure is also unfavorable. The graph that follows shows that the GDP of EU countries in percentage changes from a decline of $-4.3 \%$ in 2009 under the influence of the global economic crisis to the highest growth of $2.6 \%$ in 2017. The negative trend of the amplitude of GDP continued in 2012 and 2013. After which it reaches a growth of 2.3 in 2015 and a significant $2.6 \%$ in $2017.6 \%$ in 2017. The negative trend of the amplitude of GDP continued in 2012 and 2013. After which it reaches a growth of 2.3 in 2015 and a significant $2.6 \%$ in $2017.6 \%$ in 2017 . The negative trend in the amplitude of GDP continued in 2012 and 2013. After which it reaches a growth of 2.3 in 2015 and a significant $2.6 \%$ in 2017 .

\subsection{Analysis of EU small and medium enterprises}

According to previous research, there is a link between the number of small and medium-sized enterprises and GDP. Small and medium-sized companies have a significant impact on the business economy. The number of small and medium-sized companies is presented in Table 1. More precisely, the overview of micro, small and medium-sized companies in the EU is presented. Micro-companies represent more than a third of all companies and businesses operating in the EU market. Small and medium-sized companies represent more than $50 \%$ of the total number of companies. (World Bank Finance, 2020).

Table 1: Number of small and medium enterprises and GDP in the period from 2009 to 2019 in the EU-28 countries

\begin{tabular}{|c|r|r|r|r|r|r|r|r|r|r|r|r|r|}
\hline YEARS & 2009 & 2010 & 2011 & 2012 & 2013 & 2014 & 2015 & 2016 & 2017 & 2018 & 2019 & 2020 & SUMARY \\
\hline SMALL ENTERPRISE & 19.1 & 19.2 & 20.1 & 19.6 & 19.8 & 21.3 & 22.7 & 22.3 & 22.8 & 23.3 & 24 & 28.1 & 262.3 \\
\hline MEDIUM ENTERPRISE & 1.2 & 1.2 & 1.3 & 1.3 & 1.4 & 1.4 & 1.5 & 1.5 & 1.6 & 1.6 & 1.8 & 1.9 & 17.7 \\
\hline BDP & 10 & 10 & 11 & 11 & 11 & 11 & 12 & 12 & 12 & 13 & 13 & 13 & 139 \\
\hline
\end{tabular}

Source: Eurostat

\subsection{Regression analysis of GDP and SMEs}

In this part of the paper, we will present the connection and connection between SMEs and GDP. From the analysis of the regression model, we obtained that $b 0=5.154 ; \mathrm{b} 1=-0.566 \mathrm{~b} 2=$ 5.187 and therefore the regression equation reads: $\hat{Y}=5.154-0.566 \mathrm{X} 1+5.187 \mathrm{X} 2$ From the estimated single linear regression model we conclude the following: Relationship between the number of small and medium enterprises and GDP If the number of micro and small enterprises increases by only one a new company (employing 2 to 49 workers) this will lead to a fall in GDP per capita of 0.566 billion euros. If the number of medium-sized companies increases for only one new company (which employs from 50 to 249 workers), that will lead to an increase in GDP per capita by 5.187 billion euros. Assuming there are no small and medium-sized enterprises in the EU, that is, if the rate were equal to 0, GDP would amount to 5.154 billion euros (note: only the impact and relationship between the number of small and medium-sized enterprises and EU GDP are taken into account here). Thus, the impact of small and medium-sized enterprises on EU GDP and EU economic policy is clearly visible. With this linear regression line, the hypothesis is confirmed in an economic-mathematical way. 
Table 2: Results of the single regression analysis - small and medium enterprises and EU

\begin{tabular}{|c|c|c|}
\hline Variables & Coefficient & Std. error \\
\hline $\mathrm{b}_{\mathrm{o}}$ & 5,154 & 0,42209 \\
\hline $\mathrm{b}_{1}$ & $-0,566$ & \\
\hline $\mathrm{b}_{2}$ & 5,187 & \\
\hline $\mathrm{R}^{2}$ & 0,876 & \\
\hline $\bar{R}^{2}$ & 0,848 & \\
\hline $\mathrm{F}^{2}$ & 31,751 & \\
\hline $\mathrm{F}$ & 4,26 & \\
\hline Durbin-Watson & 1,358 & \\
\hline Pearson & 0,942 & \\
\hline
\end{tabular}

Source: Author's calculation

Figure 2: Scatterplot

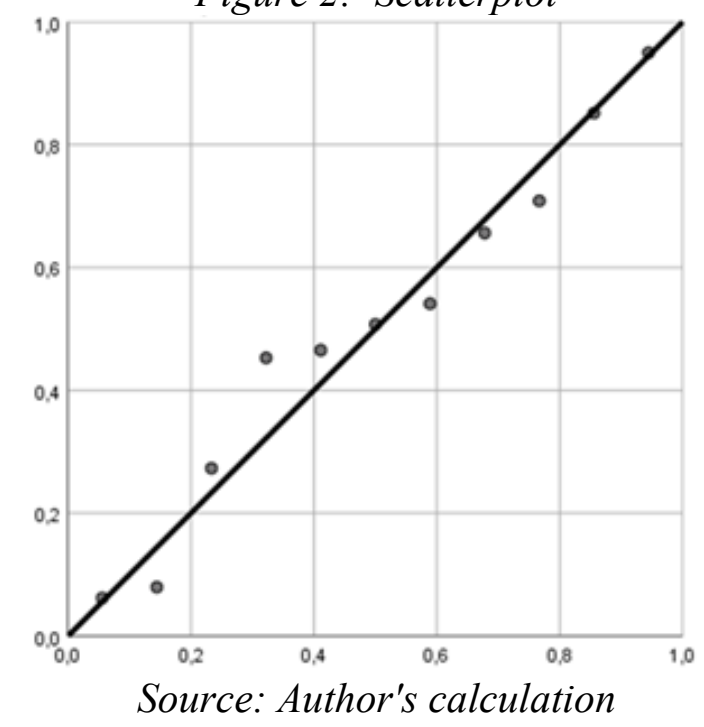

Ho: $\beta 1=0$

$\mathrm{H} 1: \beta 2 \neq 0$

$\mathrm{t}=|(\mathrm{b} 1-\beta 1) / \mathrm{Sb} 1|=5.184675305 \mathrm{t}^{\prime}=2.262$

$$
\mathrm{t}^{\prime}<\mathrm{t}
$$

With a risk of $5 \%$ and a probability of $95 \%$, the null hypothesis Ho is rejected. That is, the claim that the parameter $\beta 1$ is statistically significant, i.e., the claim that the number of small enterprises affects the total GDP is not accepted.

Hypothesis $\mathrm{H} 1$ is accepted $\mathrm{t}=|(\mathrm{b} 1-\beta 2) / \mathrm{Sb} 2|=1.8595 \mathrm{t}^{\prime}=2.262$

$$
\mathrm{t}^{\prime}>\mathrm{t}
$$

With a risk of $5 \%$ and a probability of $95 \%$, hypothesis $\mathrm{H} 1$ is accepted. That is, the claim that the parameter $\beta 2$ is statistically significant, i.e., the claim that the number of medium-sized enterprises affects the total GDP is accepted. Confidence interval b2 $=\mathrm{t}^{\prime}+\mathrm{Sb} 2 \leq \beta 2 \leq \mathrm{b} 2+\mathrm{t}^{\prime} \mathrm{Sb} 2$ $2.68409 \leq \beta 2 \leq 5.60909$ With a risk of $5 \%$, we claim that the parameter $\beta 2$ will range from 2.68409 to 5.60909 units. F test Using the set hypotheses and F test, we will evaluate the statistical significance of the model Ho: $\mathrm{R} 2=0 \mathrm{H} 1: \mathrm{R} 2 \neq 0 \mathrm{~F} 2=31,751$ With a risk of $5 \%$, ie a probability of $95 \%$ and the degree of freedom $(n k-1=9)$, using tabular values we get the value: 
$\mathrm{F}^{\prime}=4.26$ Based on the parameters we calculated $4.26<31.751$, H0 hypothesis is rejected, and $\mathrm{H} 1$ is accepted because $\mathrm{F}^{\prime}$.

Based on the parameters we calculated $4.26<31,751$, $\mathrm{H} 0$ hypothesis is rejected, and $\mathrm{H} 1$ is accepted because $F^{\prime}<F 2$ and the model is statistically significant or significant, and H1 hypothesis is confirmed - There is a significant impact of the number of medium-sized companies on total EU GDP.

The $\mathrm{F}$ test is 31.751 , while the $\mathrm{F}^{\prime}$ is 4.26 , so we can say that the evaluated model is significant. This also means accepting the hypothesis from the paper on the statistically significant simultaneous impact of EU SME growth on GDP. The Durbin-Watson value is less than 2 and is 1.358 , indicating a positive serial autocorrelation between residuals.

The coefficient of determination is $\mathrm{R} 2=0.848 * 100$ is $84.88 \%$, which means that the variation of changes in the dependent variable, i.e. GDP, is explained by changes in independent variables, ie small and medium enterprises, and the remaining $100 \%$ is the influence of other unused variables and errors. work. That is, the dependence of GDP on the number of EU SMEs is $88.88 \%$. The total GDP is affected by the number of small and medium enterprises $88.88 \%$, the rest are other factors.

Figure 3: Histogram

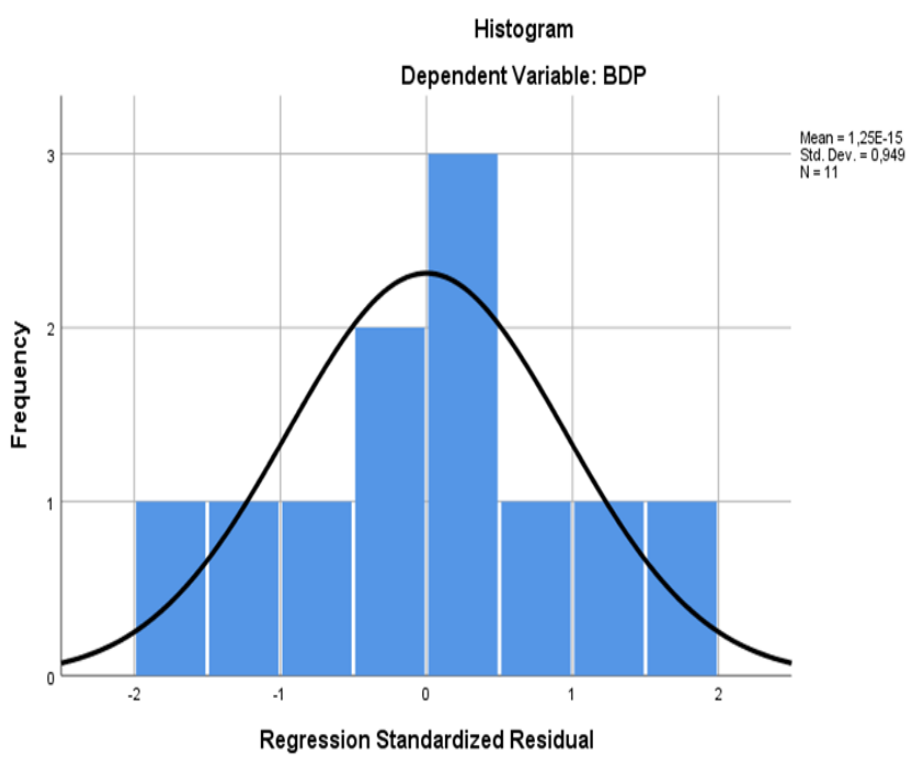

Source: Author's calculation

From the histogram we see that the standard deviation is 0.949 and that the graph of the normal distribution or curve has the so-called bell shape. The scatter plot shows a direct positive linear relationship between EU GDP and SMEs by economic-mathematical methods of estimating the single regression model.

According to the scatterplot, there is not much dispersion (deviation) between the points. The points are concentrated around the theoretical trend line, which means that the empirical data show the property of a linear trend. Total GDP and the number of SMEs in EU countries are in a direct correlation, increasing the number of SMEs leads to an increase in total GDP and from this it can be concluded that the correlation coefficient is positive. 


\section{CONCLUSION}

Small and medium enterprises are becoming the main carrier of economic development of any economy. The business environment is developing in accordance with the needs of small and medium enterprises. When adopting economic policy measures, the creators observe how these measures will affect small and medium enterprises. Observing the micro, small and medium enterprises of the EU countries, the number of newly established enterprises is constantly growing. The main goal of the paper is a two - sided prism of usefulness of this research: scientific and pragmatic. The results of the research confirm the theoretical significance and role of small and medium enterprises, as well as the need for their internalization and growth into global market leaders. Theoretical aspects of performance measurement, comparison, classification and monitoring of small and medium enterprises belong to a significant domain of business economics, which is econometrically confirmed in the paper. The practical contribution of this research is in the importance of encouraging SMEs in EU countries through internalization and globalization of business, given that changes in the environment have a much greater impact on small and medium-sized enterprises than large ones. The purpose of this research is to test the hypothesis of the correlation of macroeconomic GDP indicators on SMEs. The share of SMEs and their contribution to the total EU GDP of the EU-28 in the period from 2009 to 2019 is analyzed. When presenting the analysis, we must take into account that the initial year of the analysis was 2009 and the consequences of the economic crisis were also felt in the EU countries, which means that it also had a significant impact on macroeconomic indicators.

Summarizing the empirical results of correlation and regression analysis, we can confirm the main hypothesis that macroeconomic indicators are statistically significant and have a strong correlation with SMEs. Pearson's correlation coefficient for private consumption according to the degree of strength 0.94 , which can be characterized as a very strong correlation. It also shows that there is a linear connection and a continuous normal distribution. The histogram shows that the standard deviation is 0.949 and that the graph of the normal distribution or curve has the socalled. bell shape. The scatter diagram shows a direct positive linear relationship between total GDP and EU SMEs. The contribution of SMEs is up to $40 \%$ of national income in EU economies. These numbers are much higher and are increasing every year. The World Bank estimates that by 2030, 600 million jobs will be needed to absorb the growing global workforce and needs, making SME development a high priority for many governments around the world, which were concluded in 2019 before the new situation caused by COVID-19. Almost 10 million small and medium-sized companies produce $23 \%$ of GDP, which represents $80 \%$ of all jobs in the industrial sector and $25 \%$ of the total labor force, and thus SMEs play a key role in the total GDP of EU countries. Many developed and developing economies have realized the value of small companies. This is because small companies are characterized by dynamism, innovation, efficiency, and their small size enables a faster decision-making process.

\section{REFERENCES}

Anderson, D. (2007), Statistics for Business and Economics, 10th Edition, London, Thomas Rennie. p. 34.

Cherington, J. O., Hubbard, E. D., Luthy, D.H. (2005.) Cost Accounting: A Managerial Approach, West Group, Chicago, str. 26.

Djordjevic, D. (2016). Development Growth as a Strategic Goal Horizons series A, Social Sciences and Humanities, vol. 20. Ohrid: Faculty of Tourism and Hospitality, p. 236. 
European Commission (2019). Annual Report on European SMEs 2018/2019, SMEs start hiring again

Petkovic, S. and Berberovic, S. (2013). Economics and management of small and medium enterprises - principles and policies, Banja Luka: Faculty of Economics, University of Banja Luka.

Hagan, J. F. C. Kingman (1978). Curve Fitting and Optimal Design for Prediction", Journal of the Royal Statistical Society. Series B (Methodological),

Osborne, M. (2010). Bayesian Gaussian Processes for Sequential Prediction, Optimisation and Quadrature, University of Oxford

Singh, G. (2010). Issues faced by SMEs in the Internationalization process. International Journal of Emerging Markets, Vol. 5, No. 2, pp.153-181

Škrtić, M. and Mikić, M. (2009). Internationalization of small and medium enterprises, Scientific journal. Economic review. p. 290-311

Sorak, M. (2017). Effects of establishing entrepreneurial orientation on the performance of small and medium enterprises., Faculty of Economics, Banja Luka.

World Development Indicators \& Global Development Finance. World Bank. Avaiable at http://databank.worldbank.org/ddp/home.do accessed 08.03.2020.

https://ec.europa.eu/eurostat/statistics accessed 11.02.2020.

https://appsso.eurostat.ec.europa.eu/nui/show.do?dataset=nama_10_gdp accessed 18.03.2020. 


\section{APPENDIX}

Table 1: Worksheet required to determine the estimated multiple linear regression model

\begin{tabular}{|r|r|r|r|r|r|r|r|r|r|}
\hline & \multicolumn{1}{|c|}{$\mathbf{X}_{\mathbf{1}}$} & \multicolumn{1}{|c|}{$\mathbf{X}_{\mathbf{2}}$} & \multicolumn{1}{|c|}{$\mathbf{Y}$} & \multicolumn{1}{|c|}{$\mathbf{Y}^{\mathbf{2}}$} & \multicolumn{1}{|c|}{$\mathbf{X}_{\mathbf{1}}{ }^{2}$} & \multicolumn{1}{|c|}{$\mathbf{X}_{\mathbf{1}} \mathbf{X}_{\mathbf{2}}$} & \multicolumn{1}{c|}{$\mathbf{X}_{\mathbf{2}}{ }^{\mathbf{2}}$} & \multicolumn{1}{|c|}{$\mathbf{X}_{\mathbf{1}} \mathbf{Y}$} & \multicolumn{1}{|c|}{$\mathbf{X}_{\mathbf{2}} \mathbf{Y}$} \\
\hline 2009 & 19.1 & 1.2 & 10 & 100 & 364.81 & 22.92 & 1.44 & 191 & 12 \\
\hline 2010 & 19.2 & 1.2 & 10 & 100 & 368.64 & 23.04 & 1.44 & 192 & 12 \\
\hline 2011 & 20.1 & 1.3 & 11 & 121 & 404.01 & 26.13 & 1.69 & 221.1 & 14.3 \\
\hline 2012 & 19.6 & 1.3 & 11 & 121 & 384.16 & 25.48 & 1.69 & 215.6 & 14.3 \\
\hline 2013 & 19.8 & 1.4 & 11 & 121 & 392.04 & 27.72 & 1.96 & 217.8 & 15.4 \\
\hline 2014 & 21.3 & 1.4 & 11 & 121 & 453.69 & 29.82 & 1.96 & 234.3 & 15.4 \\
\hline 2015 & 22.7 & 1.5 & 12 & 144 & 515.29 & 34.05 & 2.25 & 272.4 & 18 \\
\hline 2016 & 22.3 & 1.5 & 12 & 144 & 497.29 & 33.45 & 2.25 & 267.6 & 18 \\
\hline 2017 & 22.8 & 1.6 & 12 & 144 & 519.84 & 36.48 & 2.56 & 273.6 & 19.2 \\
\hline 2018 & 23.3 & 1.6 & 13 & 169 & 542.89 & 37.28 & 2.56 & 302.9 & 20.8 \\
\hline 2019 & 24 & 1.8 & 13 & 169 & 576 & 43.2 & 3.24 & 312 & 23.4 \\
\hline 2020 & 28.1 & 1.9 & 13 & 169 & 789.61 & 53.39 & 3.61 & 365.3 & 24.7 \\
\hline SUMARY & 262.3 & 17.7 & 139 & 1623 & 5808.27 & 392.96 & & 3065.6 & 207.5 \\
\hline
\end{tabular}

Source: Author's calculation 